\title{
C08282
}

\section{Methodological Pluralism: Investigation into Construction Engineering and Management Research Methods}

\author{
George Agyekum-Mensah ${ }^{1}$, Andy Reid $^{2}$, and Titiloye Ayodeji Temitope ${ }^{3}$
}

\footnotetext{
${ }^{1}$ Associate Professor, School of Design, University of Greenwich, Maritime Campus, UK (corresponding author). Email: george.mensah@greenwich.ac.uk

${ }^{2}$ Assistant Professor, School of Energy, Construction and Environment, Coventry University, UK

${ }^{3}$ Project Analyst, PMO, EM-ONE Energy Solution, Toronto, Canada
}

\section{ABSTRACT}

The quantitative methodological biased debate in the 1990s in Construction Engineering and Management (CEM) Research resulted in researchers considering alternative methodologies. However, a follow up study in 2007 established that CEM remained dominated by quantitative research with only $8.4 \%$ of the studies surveyed exclusively using qualitative methods. A decade on, this remains a challenge and an update is overdue. Hence, an investigation to establish the current position regarding the methodological pluralism within CEM research was conducted. A total number of 4,166 articles spanning from 2000 to 2017 were examined from three reputable journals and tier 1 conference. The articles were categorised by the research method(s) used. Overwhelmingly, it was found there are acceptable multi-epistemologies within CEM research and there is a shifted from a dominance of quantitative to an increased utilization of qualitative methodologies and the use of mixed methodologies have shown hopeful progression. The demography of the data was also analysed and discussed. It is concluded that there is an increasing acceptance of methodological pluralism and CEM and its industry are on the verge of experiencing a competitive advantage, which could result in improved performances with utilization of balanced research methodologies (if applied appropriately).

KEYWORDS: Construction management, methodology, mixed methods, quantitative, qualitative, and research methods 


\section{INTRODUCTION}

The criticism of research methodology monopoly in CEM started in the 1990s and was instigated by Seymour and Rooke (1995). The basis was to encourage alternative approaches to conducting research in CEM. This debate initiated a challenge to the dominance of positivism and quantitative techniques in CEM research (Seymour and Rooke 1995, Seymour et al. 1997). However, the proponents of quantitative methodology criticise Seymour as being against scientific research. Runeson (1997) claims that construction as a discipline was built on pure sciences and thus suggest the dominance of quantitative methodology is consistent. The argument was sustained by suggesting that construction management is rather developed from the both sciences and social sciences; thus, both quantitative and qualitative methodology could be use appropriately to contribute relevant knowledge. Schweber (2015) argued from the view of theory but concluded by recommending the use of both qualitative and quantitate with CEM. Agyekum-Mensah (2013) asserted that debate has led to shift toward methodological pluralism. A follow up study a decade after Seymour (1995) by Dainty (2007) on methodological pluralism suggested the continued dominance of quantitative methodology and only $8 \%$ of studies surveyed exclusively used qualitative methodology. In the following decade since Dainty's study, there has been little empirical attention given to this subject, thus an update is both overdue and timely. For example, there has been a recent debate in contemporary construction conferences concerning the inappropriateness and dominant use of quantitative data collection. There was a consensus in the debate that researchers adopt quantitative survey methods regardless of the type and the nature of knowledge studied. Scholars involved in the debate suggest that the sampling process and mechanism is often inappropriate, and Javernick-Will (2018) asserts that researchers tend to ignore the contribution of theory (which is beyond the scope of this study, yet this study set the foundation for a call for debate). It is argued that papers submitted to peer reviewed 
journals go through a rigorous review process, thus the appropriateness of the method(s) adopted in published papers should have been certified by the reviewers and editors. Again, researchers such as Volker (2018) and Schweber (2015) have contributed to the recent call for debate and concluded that CEM should not be stuck within science but adopt methodological pluralism. Similarly, Harty and Leiringer (2017) questioned the future of construction research. Therefore, it is important in this era of 'call for methodological debate' to comprehensively and empirically survey the position of methodological pluralism within CEM; hence, this study. The present paper is based on the preposition that all the published papers in the selected high impact journals have gone through rigorous review process; thus, the focus is on the investigation of method(s) adopted.

The paper is organised with a review of the literature and consideration of the research design. The results, analysis and discussion follow, with a separate section dedicated to synthesis and general discussion, a conclusion was then drawn.

\section{LITERATURE REVIEW} CONSTRUCTION MANAGEMENT AS THE FIELD OF STUDY

Construction Engineering and Management (CEM) Research in this study constitutes; building, construction engineering, organisation and project management in construction, general built environment and any construction related studies. The contribution of CEM research and its industry to every economy cannot be over emphasized. Construction management is generally considered as a fairly new discipline; however, Harty and Leiringer (2017) confirmed that it is

now an internationally recognized autonomous discipline and research area. CEM makes use of methodological pluralism drawing on influences from several philosophical, as well as methodological paradigms (Fellows and Liu 2015, Knight and Ruddock 2008). Strategies used have evolved from both social and natural sciences, and accordingly both quantitative and 
qualitative data collection techniques are utilized with respective modes of inference. This has led to an abundance of recognised research methods, which have been used to contribute successfully to knowledge. Several considerations have to be taken into account when choosing which method(s) to use. Numerous philosophies of science and scientific paradigms play a significant role in this. Nevertheless, the appropriateness of the method and the conclusions thereof cannot be assessed on a philosophical position alone. Rather, it is the appropriateness of the research method, in conjunction with the applied research design to examine the research problem in its totality that is a key (Agyekum-Mensah 2013).

Practitioners and professionals in the CEM field have established the difficulty in adopting some research findings or reports (Dopson et al. 2002, Van de Ven 2007 and Bijleveld and Doree 2014). This could perhaps be due to researchers having to adopt inappropriate method(s); thus, affecting their findings. For example, Agyekum-Mensah and Knight (2017) justified that most studies on project delays adopt quantitative methodology; thus, recycling the themes within the literature. Therefore, researchers do not have a better understanding of the problem as well as no new themes are being introduced. In addition, in the pursuit of higher efficiency and productivity in the construction industry, CIOB (2016) emphasized that “...we might ask whether construction productivity is being measured in the most accurate way - are we getting the wrong impression from the data?" This is a clear justification for the use of an appropriate methodology to contribute relevant knowledge in the field of study. Harty and Leiringer (2017) questioned the future of construction management research by outlining four possible futures being convergence, retrenchment, disappearance and hybridization. In methodological aspects, Dainty (2008) suggests that the dominance of a quantitative strategy has encouraged a convention of applying a "natural science" strategy to understand social phenomena. Seymour et al. (1997) 
argue that construction management differs from natural science because the "object of study" for most construction management studies is people; thus, in order for researchers to have influence on the construction industry, the culture and conventional stance must change. Especially for the CEM research which deals with human factors, behavioural differences, and work technicality, it could be depicted that a balance is needed to enhance results.

Thus, there is arguably a consensus in literature that construction management is a field which bridges the gap between sciences and social sciences. In this $21^{\text {st }}$ century, researchers such as Andrew Dainty has been influential CEM methodological debate. Dainty (2007) started the quest with 'a review and critique of construction management research methods' which was followed with Dainty (2007b) 'A call for methodological pluralism in built environment research' and then Dainty (2008) synthesized with 'methodological pluralism in construction management research'. The focus on all these publications are closely similar emphasizing on the methodological stance. Dainty's (2007) conclusion on a survey of 107 journal papers in Construction Management and Economics (CME) Journal however did not show the general acceptance of other methodologies besides quantitative. Dainty's findings were based on a single volume of a year in the journal database which showed that $71 \%$ used quantitative methods, $8.4 \%$ used qualitative methods, $11.2 \%$ used mixed methods and $9.4 \%$ used literature review. It could be argued that the sample is small and it was only from a single volume in a particular journal to draw a robust or generalized conclusion or measure progress on the debate. However, it is a valuable study to establish the position but a decade onwards, an update on this study is long overdue. The present study worth probing wider, considering multiple publications over longer period for trend analysis which will lead to deeper analysis for generalized conclusions. Schweber (2015) presented 'putting theory to work: the use of theory in construction research' 
where she focused on data from two published construction research articles on innovation (Reichstein, Salter and Gann 2005, and Harty 2008). However, the analysis was on the citations of these articles. The main aim of this study was to discuss differences between positivist and interpretivist epistemologies, the role of theory in each and their use by construction researchers. The paper concludes with a discussion of the potential contribution of mixed research programmes, combining positivist (quantitative) and interpretivist (qualitative) research. Similarly, other studies have argued for the adoption of alternative methodologies; for example, Hallowell and Gambatese (2010) argued on the adoption of Delphi whilst Azhar et al (2010) discusses on 'action research' as they have not seen widespread use in CEM research. Zou, et al. (2014) stressed on a mixed methods research design for bridging the gap between research and practice in construction safety; and AlSehaimi et al. (2012) established the 'need for alternative research approaches in construction management'. Thus, this study is consistent with existing literature recommending an investigation or survey into methodological pluralism in CEM. KNOWLEDGE CLAIMS AND COMPETING METHODOLOGIES (PARADIGMS) According to Creswell (2014), assumptions which influence the decision of learning and its outcome are referred to as knowledge claim which are broadly referred to as paradigms. Bryman and Bell (2011) assert that a paradigm is a cluster of beliefs and dictates in a particular discipline to influence what should be studied, how research should be done and how results should be interpreted. Many fields have established methodologies (especially in sciences); however, CEM draws from both the natural and social sciences, therefore, many different paradigms compete for methodological dominance (Knight and Ruddock 2008). The two opposing epistemologies are positivism and interpretivism. Bryman and Bell (2011 p. 16) explain that the positivism focuses on "explaining human behaviour", while its contrasting epistemology, interpretivism, focuses on 
"understanding human behaviour". They added that interpretivisim is concerned with the empathic understanding of human action rather than the forces that are deemed to act on it. Schweber (2015) argued that academic fields are mainly grouped into 'domain' or 'discipline' focused. She insisted that the 'domain' focused are driven by geographical or activity type; whilst the 'discipline' focuses on a particular discipline (such as sciences or social science) as the paradigm. An understanding of the paradigms influences the type of knowledge the research contributes to, where the acceptable knowledge in a discipline is termed as epistemology. Depending on the aim, objectives, research question(s), the type of knowledge the research intends to contribute to, researchers make use of qualitative and/or quantitative strategies. Researchers such as Knight and Ruddock (2008), and Schweber (2015) provide a discussion on theory, paradigms and knowledge claim (epistemology) and they concluded the clear distinction between the competing and opposing paradigms. In addition, Agyekum-Mensah (2013) and Easterby-Smith et al. (2008) presented a close discussion on the opposing paradigms as shown Table 1.

\section{RESEARCH STRATEGY IN CEM}

Robson (2011) suggests that research strategy is the general broad orientation taken in seeking answers to research questions. The research strategy normally denotes the methodology in the combination of techniques used to enquire into a specific situation (Easterby-Smith et al. 2012). The strategy for data collection is classified in two main extremes, either the qualitative or quantitative route, albeit, both approaches could be used together. Bryman and Bell (2011) discuss a contrast between the two opposing approaches (see Table 2). Researchers can identify their position as either a qualitative, quantitative or mixed methods approach by considering the knowledge claims or strategies and methods (Creswell, 2014). The 
quantitative strategies and qualitative strategies correspond to positivism and interpretivism epistemologies respectively. Agyekum-Mensah (2013) presented a simple but clear distinction between both strategies. This is illustrated in Table 2 below.

Mixed method approach involves the practice of collecting and analysing both qualitative and quantitative data in a research. There has been an enormous enthusiasm into the triangulation or mixed method by institutions and project sponsors considering a better offer of more reliability and validity (Dainty et al. 1997). It is expected that the researchers start experiencing diversification in the approach of not using a single methodology to derive solutions, rather multiple traditions should be replicated. Schweber (2015) provides discussion on some key issues in social research as well as a reflection on the current state of construction research as a field. She concludes with a discussion of the potential contribution of mixed research methodologies, combining positivist and interpretivist research. Even with the criticism which had long caused disunion between the positivists and interpretivism, which was because of a battle of supremacy. Research based on multi-methodology are not abandoned out in the context of criticism due to its own limitations. The criticism surrounding the use of mixed methodologies and multiple methods were discussed (Bryman and Bell 2003: 480).

Agyekum-Mensah (2013) argued that designing empirical research, the researcher must ensure that both the data collected and the knowledge generated is valid and reliable. However, he emphasised that these two words are inclined closely to quantitative research as qualitative studies adopt slightly different words but similar meaning. Table 3 illustrate the terminologies used for both quantitative and qualitative research (adapted from Agyekum-Mensah, 2013 and Bryman and Bell 2011).

Therefore, regardless the method(s) used the study should be conducted with a robust 
methodology where the data and/or findings are comprehensively evaluated as per Table 3 . The method adopted also reflect the type of contribution of the research.

\section{THE RESEARCH DESIGN}

In this study, the research method adopted was critical document analysis spanning 17 years, where a total of four key publications were analyzed. The study focused on articles submitted to three key journals from the USA and UK, and tier 1 conference proceedings in the UK. The publications consisted of Journal of Construction Engineering and Management (JCEM), Construction Management and Economics (CME), Engineering, Construction, Architectural Management (ECAM) and Association of Researchers in Construction Management (ARCOM) proceedings. The criteria and justification for choosing these four main sources include: 1) geographic location, 2) quality of publishers, 3) scope and content, 4) ranking and the impact, and 4) accessibility and covering CEM.

A documentary review and analysis of four data sources were adopted for this study. A document analysis is a research method which involves a review or assessment both printed and electronic materials (Bowen 2009). They are essentially references to existing data from journals or companies archive, this contrasts with the use of primary data.

In this light, a table was specifically created using Microsoft Excel spreadsheet which includes the title of article, journal title, year, country, method adopted and reference.

\section{SAMPLING}

A total of 4,166 articles where analyzed spanning from the year 2000 to 2017 within CME, ECAM, JCME, and ARCOM which are all the articles published within the duration, this period was selected to cover the whole of the $21^{\text {st }}$ century. Again, although it is a follow-up study from Dainty (2007), Dainty's study was only based on a single year, single volume and single publication within CME. Therefore, it is important in this study to survey multiple publications, four publications were considered and over a greater time period (2000 to 2017). Table 4 outlines 
the details in numbers and percentages of the articles and/or documents analysed.

These database were chosen out of the various databases of journals: JCEM an international journal based in the USA, a quartile 1 was analysed. This journal combines articles from construction and engineering management and published by ASCE. In addition, CME and ECAM, prominent journals in CEM based in the UK were critical analysed. The former is published by Taylor and Francis Publishers whilst the latter is by Emerald which are renowned names in publishing. All the journals are highly ranked upper quartile with high impact within CEM covering the scope of research methodology debates. Also, to improve the quality of findings and give it a generalized perspective, ARCOM, a tier 1 conference was reviewed (SC Imago Journal Rank 2017). As per the study of Dainty (2007), which was published within CME, four general categorizations were adopted which are: 1). quantitative - unambiguously adopting quantitative methods rooted in a positivist research paradigm; 2). qualitative - unambiguously adopting qualitative methods rooted in an interpretative research paradigm; 3). mixed methods comprising a combination of both positivism (quantitative) and interpretivism (qualitative) research methods; and 4). Literature review - not utilizing empirical research methods. The data shows that on average 85 articles are published per year by ARCOM, 77 articles by CME, 37 articles by JCEM and 36 by ECAM. CME publishes averagely more than JCEM and ECAM put together per year.

\section{METHOD OF DATA ANALYSIS}

Statistical analysis was applied to the data acquired from the review of documents of the various journals. Descriptive and inferential statistical analysis was adopted using a Microsoft Excel spreadsheet and was presented using tables and figures. All the data from different publications was inputted on a Microsoft Excel spreadsheet. The 'data' tab and the 'find' function was used 
to highlight the various methods adopted and several adopted methods were studied prior to a mean for each method being derived. An individual publication was analysed and a cross analysis was conducted to ensure a robust synthesis. A further analysis was conducted on the demography of the articles submissions in each publications. The categories were the USA, UK and the rest of the world. The findings of the present study were qualitatively evaluated by seven senior CEM methodologist and their comments were considered and incorporated in the study.

\section{RESULTS, ANALYSIS AND DISCUSSION}

Each journal was analysed and discussed separately and a cross discussion was made afterward. Supplementary data information sheet presents an individual data analyses. It is necessary to state that the main objective is to investigate the research method(s) used in the twenty-first century but not to consider the appropriateness of the method(s) in the submissions in all the different publications. This is because the sources of data used goes through a highly rigorous peer review process and appropriateness of method would have been considered.

\section{COLLATION OF DATA FROM CME}

Quantitative methods have been mostly utilized between the period of 2000 and 2008 before showing regular decline in use to 2017. This signifies that the qualitative methods were inadequately utilized between the year 2000 and 2007, as quantitative was dominant during this period. This was consistent with the idea behind the call for the methodological debate and Dainty's (2007) findings of the dominance of quantitative research in CEM. Qualitative studies gained momentum from the year 2008 and have maintained a steady growth. Perhaps this is due to the methodological debate and the awareness of the opposing methodologies to contribute to knowledge within CEM research. Little change in the use of literature review as a research method over the period under scrutiny. 
It was found from the 17 years data that averagely $39.9 \%$ of journals adopted qualitative research methods; $38.3 \%$ adopted quantitative research method exclusively; $14.2 \%$, mixed methods; $7.6 \%$, literature review. There is approximately $2 \%$ difference between the use of qualitative and quantitative methods. This signifies the close margin and nearly equal use of both quantitative and qualitative methods exclusively within CME. This is a significant improvement and change from the study Dainty (2007) where only $8.4 \%$ of the studies surveyed used qualitative methods exclusively. Figure 1 present the trend analysis graphically. COLLATION OF DATA FROM ECAM

The qualitative methods experienced some growth between the period of 2000 and 2002 before falling in 2003. However, since 2004 it has experienced a noticeable rise. It is safe to conclude that on average, qualitative method has been highly acceptable within ECAM. In addition, mixed methods were very low in 2002 but increased in 2003. It has shown signs of increased utilisation compared to the early 2000 s. In comparison quantitative methods have been well utilized between the period of 2000 and 2008 before showing signs of declining. This does not demonstrate the relevance of one method over the other but reveal the acceptance of methodological pluralism.

Evaluating the ECAM journal, it shows that $39.9 \%$ of journals comprehensively use the qualitative research methods; $31.7 \%$ embraced quantitative research method; $21.9 \%$, mixed methods; $6.4 \%$, literature review.

Figure 2 presents the graphical analysis of the articles reviewed and it shows close consistent use of the methods especially the qualitative and qualitative. However, averagely mixed methods has 
some gains in the recent times.

\section{COLLATION OF DATA FROM ARCOM}

Whist it is noted that ARCOM is not a journal, it is a tier 1 peer review conference internationally. The analysis of ARCOM connotes that qualitative methods had built recognition amongst researchers with the highest usage in 2013 when over $61 \%$ of the published submissions exclusively used this method. Qualitative accounted to $42 \%$ of the overall total of analysed submissions. The usage of quantitative has be relegated to the second place; however its relevance has been continuous with a total of almost $28 \%$. Mixed method has equally received acceptance with a total of $17 \%$ and literature review accounting to $13 \%$ of the total analyses. Figure 3 presents the graphical analysis of ARCOM articles reviewed and it shows a decline use of all the methods but steeply in both qualitative and quantitative use from 2010 . This could be due to reduction in the number of publication rather than usage of a selected method(s). Notwithstanding, qualitative is favourite used of the methods.

\section{COLLATION OF DATA FROM JCEM}

JCEM is a quartile one journal and is part of ASCE (American Society of Civil Engineers) collections of journals. In this journal the use of quantitative has been dominant except in some specific years to wit 2003, 2010 and 2013. Arguably, this might not be surprising as the collections of journal is inclined toward pure sciences - civil engineering. Yet from 2016 qualitative studies gained some momentum. This could be argued that even in this journal qualitative methods are being recognized and used as acceptable research methods. In total, there is close usage of quantitative and qualitative with $41 \%$ and $40 \%$ respectively. The general acceptance and usage of different methods demonstrate the acceptance of methodological pluralism within CEM also in this publication, which is a challenge to the findings in the existing 
literature. Figure 4 demonstrate the graphical analysis of the articles reviewed in JCEM.

\section{SYNTHESIS AND DISCUSSION}

In this section, a synthesis of the data from CME, ECAM, ARCOM and JCEM to draw a comprehensive summary of findings will be presented. Discussions are categorized in quantitative, qualitative mixed methods and literature review. This is followed by an overall summary of the findings. Table 5 presents the analysis of the synthesis of quantitative methods; Table 6 illustrates the analysis of the synthesis of qualitative; Table 7 for the synthesis of the analysis of mixed methods and Table 8 reveals the analysis of the literature review.

\section{COLLATION OF TOTAL QUANTITATIVE METHODS}

$<$ Insert Table 5 $>$

The findings show that the use of quantitative has been consistent for the last 17 years averaging $34 \%$ whilst qualitative, has averaged $41 \%$ yearly.. This finding is an update of the 1990 s debate of quantitative dominance in CEM, and updates Dainty's (2007) findings of only $8.4 \%$ usage of qualitatively exclusively in CME. It should be noted that Dainty's study focused only on a volume in a single year. This could be due to the tediousness of the data collection process. This study concludes that qualitative has increased its acceptance in CEM and the use of mixed methods averaged $16 \%$ years with literature review averaging $10 \%$. Figure 5 presents the trend analysis.

\section{COLLATION OF TOTAL QUALITATIVE METHODS}

Table 6 and Figure 6 present the synthesis of the analysis of qualitative in all the publications. In Figure 6, it is seen that qualitative has maintained a consistent use in all the journal but ARCOM. There was a decline of use from 2010 but stabilised in 2014 and 2015 but started inclining from 2016. There has been a general acceptance of this method among construction management 
researchers with a total of almost $41 \%$ of all articles (see Table 6 ).

COLLATION OF TOTAL MIXED METHODS

From Tables 7 and 8, it was found that almost $10 \%$ used literature review and $16 \%$ for the use of mixed methods. The general trend shows an acceptance of mixed methods as well as literature review. Figure 7 shows a consistent featuring in all the publications except ARCOM. This is a shows evidence of progression.

\section{COLLATION OF TOTAL LITERATURE REVIEWS}

From Table 8 and Figure 8, it shows that literature is gaining an acceptance albeit not compared to other methods. This method is popular within ARCOM publication, which could be understood as it is a conference proceedings thus attracting more $\mathrm{PhD}$ researchers. Interestingly, the method struggles a bit within JCEM and this could be argued that the gatekeepers (such as editors and reviewers) may not consider this method an acceptable way to contribute to knowledge.

THE TREND OF METHODOLOGIES IN CEM

\section{COLLATION OF TOTAL ARTICLES (PERCENTAGE IN PARENTHESIS)}

Analysis in Table 9 and Figures 9, 10 and 11 summaries the trend and categorisation of research methods used in CEM. This indicates the total of specific methods used against each other to draw a conclusion. In addition, Tables S1 to S4 provide the analysis on individual data source (CME, ECAM, ARCOM, and JCEM). This infers prior to 2007, quantitative methods were mostly utilized but the researchers and the industry has embraced other methodologies such as qualitative methods and mixed methods of research over the years. In respect to that, mixed methods and literature review has gained more acceptance subsequently. 
The Figure 11, interprets the summary of the most commonly used methods in the twenty-first century (based on the articles submitted to CME, ARCOM, ECAM, and JCEM). It connotes that $33.0 \%$ of journals supported the use of quantitative research methods; $41.4 \%$ utilised qualitative research methods; $16.0 \%$ mixed methods, while $9.6 \%$ adopted literature review. Many organizations and researchers have adopted the use of qualitative data for organizational based research to contribute to successful knowledge

\section{ANALYSIS OF THE DEMOGRAPHY OF THE SUBMISSIONS}

In this study the demography of the submissions from all the publications were considered. This was focused on the UK, USA and others (the rest of the world). The UK and USA were analysed as the publications considered in this study were from these countries (CME, ECAM and ARCOM are from the UK) and (JCEM is in USA). Tables 10, 11, 12 and 13 present demography of CME, ECAM, JCEM and ARCOM respectively.

The analysis from Table 10 shows that $34 \%$ of the articles in CME originate in the UK. Literature review and mixed methods account for $4 \%$ each, whilst quantitative and qualitative are $10 \%$ and $16 \%$ respectively. This indicates an average rise in the use of qualitative methods in the UK studies. However, the studies from the USA in CME is still slightly dominated by quantitative studies. This is consistent with the studies from 'rest of the world' which is dominated with quantitative studies Figure 12 indicates that submissions from USA and the rest of the world to CME is still dominated with quantitative studies; however, studies from the UK has embraced the use of qualitative.

In ECAM qualitative is slightly ahead of the use of quantitative from the UK and USA studies. Nevertheless, from Tables 10,11, 12 and 13, 'the rest of the world' still conducts more quantitative than qualitative studies. There is a close contest between qualitative and quantitative 
studies in the submissions from the USA, yet, there is a big gap (10\%) between the use of qualitative and quantitative studies from the UK submissions. Most of the articles are from the 'rest of the world' which is 55\% and 57\% within ECAM and CEM respectively. Whilst the submissions from the USA are relatively low, in single figures in all publications except JCEM JCEM submissions are dominated by studies from the USA, which is $67 \%$ even more the UK and the 'rest of the world' combined. However, in terms of methods used are very close competition between quantitative and qualitative from all the regions. This shows equally acceptance of the methodological pluralism in CEM. Equally, ARCOM is dominated with submissions from the UK accounting for $65 \%$ of the total submissions and only $1 \%$ from the USA. There is a close usage between qualitative and quantitative from the 'rest of the world' submissions. However, qualitative studies from the UK accounting to $28 \%$ of submissions. This study established that qualitative studies dominated the UK submissions, whilst it is close usage in the trend between qualitative and quantitative from USA and the 'rest of the world'. Other research methods such as mixed methods and literature review progressively being accepted.

\section{DISCUSSION}

Generally, over the past years, the amount of research being carried out has increased due to an increased number of doctoral researchers in the construction management field and an expansion of academic facilities and departments (Hughes 2008). It would have been expected that the methods adopted in these studies should diversify and broaden accordingly. However, it is evident that they are still clustered around the quantitative and qualitative, although there is a shift towards a more qualitative environment, with mixed methods and literature review gaining appreciation. The findings of this research generated from the review of past journals, a total of 4166 (i.e. JCME, CME, ARCOM and ECAM) evidences that the methodology adopted for CEM 
research has shifted from the adoption of a quantitative methodology toward the qualitative methodology. This is contrary to the argument in the 1990s and earlier dates where the positivist paradigm (quantitative) was more prevalent in CEM. In studies such as Bresnen (2013), it was asserted that due to the scientific and social science background of CEM, a positivist stance was still maintained. Whilst, Dainty (2007) argued that CEM was still rooted firmly within the positivist methods, a view supported by (Fellows and Lui 2015). Dainty's findings suggested the qualitative is the least favourite method used. As compared to the 107 journal papers reviewed (Dainty 2007), this research was executed by reviewing a larger sample size of 4,166 journals in four different publications in UK and USA over a longer time span of 17 years in order to get more accurate and up to date results.

The shift indicates that other epistemological positions (knowledge) have been accepted in the CEM. It was found that $41.4 \%$ qualitative methods; $33.0 \%$ quantitative method; $16.0 \%$ mixed methods and $9.6 \%$ literature review. This shows that the dominance of quantitative methods has been broken and that this investigation shows that the greater part of CEM research has accepted methodological pluralism. It is also found that the UK studies have embraced the use of qualitative techniques over quantitative techniques when compared to the USA and the rest of the world.

This finding could be claimed as a move in the right direction to aid construction firms to deal with market, people and processes at all project levels. Radosavljevic (2001) argued that despite the numerous pieces of research carried out in the construction industry, the industry still lags behind compared to other industries in terms of productivity, profitability and performance. This is arguably attributed to the dominance of a particular epistemology, thus studies do not truly address the issues in the industry. For example, Robinson and Carrillo (2001) expressed how 
knowledge management can be linked to business performance and it was argued that a key to these improvements is creativity in knowledge, mixed methods, and multi- methodologies. Similarly, Mootanah (1998) and Gunning, (2001) indicated that to achieve beneficial crisis management research, traditional methodology of risk management should be combined with soft systems methodology. Additionally, Treloar et al. (2000) argue the need for more comprehensive research methods to enhance engineering judgements. The combination of results garnered from the various use of methods produces better research. This depicts the relevance of combining methodologies. In the findings of this research, the trend of mixed methodologies is also fast growing and it is a positive sign for the industry.

The findings show the CEM researchers embrace multi- methodologies to enhance more balanced results. The results of this investigation will help determine the present state of the construction industry research papers and how researchers will handle perceived issues for the advancement of more quality results from research carried out.

However, establishing the methodological position in CEM in terms of literature review, quantitative, qualitative or a result of mixed methods does not ignore or accept the possibility that these studies are still largely stuck in the positivist framing (see Schweber 2015). Again, the findings do not support or ignore the argument that many qualitative studies tend to be in positivist settings.

\section{CONCLUSION}

This study highlights the methodological pluralism position and updates on the call for debate on acceptable methodologies in CEM research. This is first study to provide a longitudinal empirical investigation (spanning 17 years data) into methodological pluralism after the methodological debate in the 1990s. The very essence of the study was not to support any particular method(s) 
but to establish the acceptable research method(s) and epistemologies in CEM. Also, the outcome of this research provides statistical evidence about the methodologies and an update of the debates. The increase acceptance of methodological pluralism in CEM and its industry are positive to enhance performances and processes with utilization of balanced research methodologies. The findings of this research, based on an analysis of 4,166 articles spanning from 2000 to 2017 , show that $41.4 \%$ utilize qualitative methods; $33.0 \%$ quantitative method; $16.0 \%$ mixed methods and $9.6 \%$ literature review. It is concluded that the methodological debates in the 1990s have contributed to a shift in CEM research methodological pluralism. This will enable a balanced contribution of knowledge to the construction industry and an appropriate application to both people and process needs. The study will also provide young and mid-career CEM researchers the methodological position.

This study did not consider the appropriateness of the research method(s) used or the appropriateness of the sampling or the population of the participants which could be considered for another call for debate. Again, this study does not draw into the debate or assertion that CEM is still stuck in positivist paradigm. Finally, it is also worth noting that studies that end up in these publications go through quite rigorous sifting through the peer-review process. As such, one needs to qualify that any detection of a methodological shift is also a result of what gets left in and what gets left out by the gatekeepers in the field - reviewers, editors, and so forth.

\section{Data Availability Statement}

Data generated or analyzed during the study are available from the corresponding author by request. Information about the Journal's data-sharing policy can be found here:

http://ascelibrary.org/doi/10.1061/(ASCE)CO.1943-7862.0001263. 


\section{Acknowledgement}

We would like to thank all the senior methodologists in CEM for their constructive feedback

received during the evaluation stage to improve this submission, we are grateful.

\section{Supplemental Data}

Tables S1-S4 are available online in the ASCE Library (www.ascelibrary.org).

\section{REFERENCES}

Agyekum-Mensah, G. (2013) The Development of an Innovative Sustainable Total Planning and Control System for Construction Projects, PhD Thesis, Nottingham Trent University

Agyekum-Mensah, G. and Knight, A. D. (2017) The professionals' perspective on the causes of project delay in the construction industry", Engineering, Construction and Architectural Management, Vol. 24 Issue: 5, pp.828-841AlSehaimi, A., Koskela, L. and Tzortzopoulos, P., (2012) Need for alternative research approaches in construction management: Case of delay studies. Journal of Management in Engineering, 29(4), pp.407-413.

Azhar, S., Ahmad, I. and Sein, M.K., (2009) Action research as a proactive research method for construction engineering and management. Journal of Construction Engineering and Management, 136(1), pp.87-98.

Bowen, G. A. (2009) Document Analysis as a Qualitative Research Method, Qualitative Research Journal, 9 (2), 27-40

Bresnen, M., (2013). Insights on site: research into construction project organizations. In Doing Research in Organizations (RLE: Organizations) (pp. 44-62). Routledge.

Bryman, A. and Bell, E. (2011). 3rd ed. Research in business studies, Oxford University Press CIOB (2016) Productivity in Construction: Creating a Framework for the Industry to Thrive, Bracknell, UK

Creswell, J. W. (2014) Research Design: Qualitative, Quantitative, and Mixed Methods Approaches, 4th ed., SAGE Publications Inc., California, USA

Dainty, A. (2008) Methodological Pluralism in Construction Management Research, In Knight A., and Ruddock, L., ed.; Advance Research Method in Built Environment; WileyBlackwell, Oxford. 1-12.

Dainty, A. R. J (2007) A review and critique of construction management research methods. In Proceedings of Construction Management and Economics 25th Anniversary Conference (Hughes, W. Ed.), University of Reading, 16 - 18 July. p.1533 - 1543.

Dainty, A.R.J. (2007b) A call for methodological pluralism in built environment research, in Egbu, C.O. and Tong, M.K.L. (Eds), Proceedings of 3rd Scottish Conference for Postgraduate Researchers in the Built \& Natural Environment (PRoBE), Glasgow Caledonian University, Glasgow, 20-22 November, pp. 1-10.

Dainty, R., Bagilhole, R., and Neale, R. (1997) 'Analytical Strategies for Dealing with 
Qualitative Data.' Construction Management Research. 2, (1) 15-17

Dopson, S., Fitzgerald, L., Ferlie, E., Gabbay, J. and Locock, L. (2002) No magic targets Changing clinical practice to become more evidence based, Health Care Management Review, 27(3), 35-47.

El-Diraby, T.A. and Gill, S.M., (2006) A taxonomy for construction terms in privatizedinfrastructure finance: supporting semantic exchange of project risk information. Construction Management and Economics, 24(3), pp.271-285.

Fellows, R., and Liu, A. (2015) Research Methods for Construction 4th Ed. New York: John Wiley \& Sons, Incorporated

Gruber, T. (1993) A translation approach to portable ontology specification, Knowledge system laboratory, Technical Report. Stanford, CA: Stanford University.

Hallowell, M.R. and Gambatese, J.A., (2009) Qualitative research: Application of the Delphi method to CEM research. Journal of construction engineering and management, 136(1), pp.99-107

Harty, C. and Leiringer, R. (2017) The futures of construction management research.

Construction Management and Economics, 35 (7). pp. 392-403

Hughes, W., ed. (2008) Proceedings of the inaugural construction management and economic 'P ast, Present and Future' conference CME25, 16-18 July 2007, University of Reading, UK. School of Construction Management and Engineering, University of Reading, Reading, pp 1846.

Khosrowshahi, F. and Alani, M. (2003) 'Event and effect model of building maintenance'. Association of Researchers in Construction Management, 2, 3-5.

Knight, A., and Ruddock, L., (2008). Advance Research Method in Built Environment; WileyBlackwell, Oxford

Javernick-Will, A. (2018) Rationale: the necessary ingredient for contributions to theory and practice, Construction Management and Economics, 36:8, 423-424, DOI: 10.1080/01446193.2018.1487910

Mootanah, D.P., (1998) Developing an integrated risk and value management framework for construction project management. In Proceedings of the 14th Annual Conference of the Association of Research in Construction Management (ARCOM), Reading University, Reading, 2, 448-457.

Robinson, H. and Carrillo, P. (2001) Linking Knowledge Management to Business Performance in Construction Organisations. Reading: ARCOM Association of Researchers in Construction Management. Available at: http://www.arcom.ac.uk (accessed 15 June 2017) Rooke, J.A. and Seymour, D. (1995) 'The Culture of the Industry and the Culture of Research. Construction Management and Economics, 13 (6), 511-523

Runeson, G. (1997) The role of theory in construction management research: comment, Construction Management and Economics, 15, 299-302.

Schweber, L. (2015) Putting theory to work: the use of theory in construction research. Con struction Management and Economics, 33 (10) 840 - 860. 
SCImago Journal Rank (2017) Journal Rankings on Building and Construction [online] Available from <http://www.scimagojr.com/journalrank.php?category=2215> [1 July 2017]

Seymour, D., Crook, D. and Rooke, J. (1997) The role of theory in construction management: a call for debate. Construction Management and Economics, 15, 117-9

Treloar, G.J., Love, P.E.D., Faniran, O.O., and Iyer-Raniga, U. (2000) 'A Hybrid Life Cycle Assessment Method for Construction'. Construction Manag. and Economics, 18 (1), 5-9

Van de Ven, A.H. (2007) Engaged Scholarship: A Guide for Organizational and Social Research, Oxford University Press, Oxford.

Volker, L. (2018) Looking out to look in: inspiration from social sciences for construction management research, Construction Management and Economics, DOI:

10.1080/01446193.2018.1473619 
Table 1: Comparison of opposing methodologies - paradigms (positivism and interpretivism)

\begin{tabular}{|l|l|l|}
\hline Theory & Deductive (testing of theory) & Inductive (generation of theory) \\
\hline Epistemology & Positivism & Interpretivism \\
\hline Ontology & Objectivism & Constructionism \\
\hline Strategy & Quantitative & Qualitative \\
\hline The Observer & Sust be independent & Is part of what is being observed \\
\hline Human interest & Should be relevant & Are the main drivers of science \\
\hline Explanations & Must demonstrate causality & $\begin{array}{l}\text { Aim to increase general } \\
\text { understanding of the situation }\end{array}$ \\
\hline Research progresses & Hypotheses and deduction & $\begin{array}{l}\text { Gathering rich data from which } \\
\text { ideas are induced }\end{array}$ \\
\hline Concepts & $\begin{array}{l}\text { Need to be operational so that } \\
\text { they can be measured }\end{array}$ & $\begin{array}{l}\text { Should incorporate stake holders } \\
\text { perspectives }\end{array}$ \\
\hline Units of analysis & $\begin{array}{l}\text { Should be reduced to its } \\
\text { simplest terms }\end{array}$ & $\begin{array}{l}\text { May include the complexity of } \\
\text { 'whole' situation }\end{array}$ \\
\hline Generalisation through & Statistical Probability & Theoretical abstraction \\
\hline Sampling requires & $\begin{array}{l}\text { Large numbers selected } \\
\text { randomly }\end{array}$ & $\begin{array}{l}\text { Small numbers of cases chosen } \\
\text { for specific reasons }\end{array}$ \\
\hline
\end{tabular}

Table 2: Comparison of opposing strategies (quantitative and qualitative)

\begin{tabular}{|l|l|}
\hline Quantitative & Qualitative \\
\hline Numbers & Words \\
\hline Researcher's opinion & Participants opinion \\
\hline Distance interaction & Close interaction \\
\hline Theory testing & Theory generating \\
\hline Static & Process \\
\hline Structured & Unstructured \\
\hline Generalization & Relative understanding \\
\hline Hard and reliable data & Rich and valid data \\
\hline Macro & Micro \\
\hline Artificial settings & Natural settings \\
\hline Behaviour & Meaning \\
\hline
\end{tabular}


Table 3: Comparison of evaluation criteria for the opposing strategies (quantitative and qualitative)

\begin{tabular}{|l|l|l|}
\hline Description & Quantitative & Qualitative \\
\hline How believable are the findings? & Validity (Internal) & Credibility \\
\hline Do the findings apply to other context? & Validity (External) & Transferability \\
\hline Are the findings likely to apply other times? & Reliability & Dependability \\
\hline $\begin{array}{l}\text { Has the researcher allowed his/her values } \\
\text { intrude to a high degree? }\end{array}$ & Objectivity & Conformability \\
\hline
\end{tabular}

Table 4: Details of the Documents or Articles Sampling

\begin{tabular}{|l|l|l|}
\hline Journal Database & Number of Journals Reviewed & Percentage (\%) \\
\hline Total Number of Journals & $\mathbf{4 1 6 6}$ & $\mathbf{1 0 0}$ \\
\hline CME & 1387 (av. 77 per year) & 33.29 \\
\hline ECAM & 653 (av. 36 per year) & 15.67 \\
\hline ARCOM & 1454 (av. 85 per year) & 34.90 \\
\hline JCEM & 672 (av. 37 per year) & 16.14 \\
\hline
\end{tabular}


Table 5: Total Quantitative Methods - Synthesized

\begin{tabular}{|c|c|c|c|c|c|c|c|c|c|c|c|}
\hline \multirow{2}{*}{ YRS } & \multicolumn{5}{|c|}{ TOTAL JOURNALS REVIEWED } & \multicolumn{6}{|c|}{ QUANTITATIVE METHOD } \\
\hline & CME & ECAM & ARCOM & JCEM & TOTAL & CME & ECAM & ARCOM & JCEM & TOTAL & $\%$ \\
\hline 2000 & 92 & 36 & 84 & 60 & 272 & 29 & 13 & 28 & 29 & 99 & $36.4 \%$ \\
\hline 2001 & 78 & 37 & 95 & 75 & 285 & 27 & 8 & 20 & 26 & 81 & $28.4 \%$ \\
\hline 2002 & 60 & 38 & 76 & 75 & 249 & 40 & 8 & 22 & 32 & 102 & $41.0 \%$ \\
\hline 2003 & 73 & 18 & 84 & 87 & 262 & 40 & 4 & 26 & 33 & 103 & $39.3 \%$ \\
\hline 2004 & 89 & 36 & 135 & 82 & 342 & 50 & 13 & 41 & 24 & 128 & $37.4 \%$ \\
\hline 2005 & 85 & 35 & 121 & 17 & 258 & 45 & 11 & 59 & 9 & 124 & $48.1 \%$ \\
\hline 2006 & 107 & 36 & 97 & 20 & 260 & 56 & 6 & 20 & 9 & 91 & $35.0 \%$ \\
\hline 2007 & 102 & 37 & 83 & 21 & 243 & 45 & 13 & 28 & 11 & 97 & $39.9 \%$ \\
\hline 2008 & 94 & 36 & 104 & 25 & 259 & 36 & 15 & 27 & 14 & 92 & $35.5 \%$ \\
\hline 2009 & 88 & 36 & 133 & 23 & 280 & 35 & 10 & 30 & 13 & 88 & $31.4 \%$ \\
\hline 2010 & 91 & 34 & 149 & 23 & 297 & 34 & 9 & 37 & 8 & 88 & $29.6 \%$ \\
\hline 2011 & 76 & 36 & 95 & 24 & 231 & 21 & 14 & 22 & 11 & 68 & $29.4 \%$ \\
\hline 2012 & 66 & 36 & 65 & 22 & 189 & 23 & 15 & 14 & 9 & 61 & $32.3 \%$ \\
\hline 2013 & 71 & 54 & 31 & 23 & 179 & 16 & 16 & 7 & 10 & 49 & $27.4 \%$ \\
\hline 2014 & 77 & 34 & 30 & 25 & 166 & 16 & 11 & 8 & 12 & 47 & $28.3 \%$ \\
\hline 2015 & 57 & 37 & 27 & 21 & 142 & 10 & 13 & 7 & 10 & 40 & $28.2 \%$ \\
\hline 2016 & 56 & 41 & 46 & 23 & 166 & 4 & 15 & 7 & 10 & 36 & $21.7 \%$ \\
\hline 2017 & 25 & 35 & 0 & 26 & 86 & 4 & 13 & 0 & 5 & 22 & $25.6 \%$ \\
\hline Total & 1387 & 652 & 1455 & 672 & 4166 & 531 & 207 & 402 & 275 & 1415 & $34.0 \%$ \\
\hline
\end{tabular}


Table 6: Total Qualitative Methods - Synthesised

\begin{tabular}{|r|c|c|r|r|r|r|r|r|r|r|r|r|r|}
\hline \multirow{2}{*}{ YRS } & \multicolumn{3}{|c|}{ TOTAL JOURNALS REVIEWED } & \multicolumn{7}{|c|}{ QUALITATIVE METHOD } \\
\cline { 2 - 13 } & CME & ECAM & ARCOM & JCEM & TOTAL & CME & ECAM & ARCOM & JCEM & TOTAL & $\%$ \\
\hline 2000 & 92 & 36 & 84 & 60 & 272 & 38 & 15 & 20 & 19 & 92 & $33.8 \%$ \\
\hline 2001 & 78 & 37 & 95 & 75 & 285 & 33 & 19 & 30 & 30 & 112 & $39.3 \%$ \\
\hline 2002 & 60 & 38 & 76 & 75 & 249 & 10 & 21 & 27 & 22 & 80 & $32.1 \%$ \\
\hline 2003 & 73 & 18 & 84 & 87 & 262 & 18 & 6 & 34 & 37 & 95 & $36.3 \%$ \\
\hline 2004 & 89 & 36 & 135 & 82 & 342 & 26 & 15 & 57 & 45 & 143 & $41.8 \%$ \\
\hline 2005 & 85 & 35 & 121 & 17 & 258 & 21 & 18 & 42 & 3 & 84 & $32.6 \%$ \\
\hline 2006 & 107 & 36 & 97 & 20 & 260 & 32 & 20 & 37 & 8 & 97 & $37.3 \%$ \\
\hline 2007 & 102 & 37 & 83 & 21 & 243 & 33 & 12 & 27 & 8 & 80 & $32.9 \%$ \\
\hline 2008 & 94 & 36 & 104 & 25 & 259 & 42 & 10 & 53 & 10 & 115 & $44.4 \%$ \\
\hline 2009 & 88 & 36 & 133 & 23 & 280 & 38 & 17 & 61 & 7 & 123 & $43.9 \%$ \\
\hline 2010 & 91 & 34 & 149 & 23 & 297 & 37 & 10 & 76 & 11 & 134 & $45.1 \%$ \\
\hline 2011 & 76 & 36 & 95 & 24 & 231 & 37 & 9 & 45 & 9 & 100 & $43.3 \%$ \\
\hline 2012 & 66 & 36 & 65 & 22 & 189 & 32 & 9 & 35 & 7 & 83 & $43.9 \%$ \\
\hline 2013 & 71 & 54 & 31 & 23 & 179 & 44 & 23 & 19 & 12 & 98 & $54.7 \%$ \\
\hline 2014 & 77 & 34 & 30 & 25 & 166 & 40 & 12 & 12 & 9 & 73 & $44.0 \%$ \\
\hline 2015 & 57 & 37 & 27 & 21 & 142 & 33 & 13 & 12 & 8 & 66 & $46.5 \%$ \\
\hline 2016 & 56 & 41 & 46 & 23 & 166 & 31 & 18 & 27 & 8 & 84 & $50.6 \%$ \\
\hline 2017 & 25 & 35 & 0 & 26 & 86 & 8 & 13 & 0 & 15 & 36 & $41.9 \%$ \\
\hline Total & 1387 & 652 & 1455 & 672 & 4166 & 553 & 260 & 614 & $\mathbf{2 6 8}$ & $\mathbf{1 6 9 5}$ & $\mathbf{4 0 . 7 \%}$ \\
\hline
\end{tabular}


Table 7: Total Mixed Methods - Synthesised

\begin{tabular}{|c|c|c|c|c|r|r|r|r|r|r|c|}
\hline \multirow{2}{*}{ YRS } & \multicolumn{3}{|c|}{ TOTAL JOURNALS REVIEWED } & \multicolumn{7}{|c|}{ MIXED METHODS } \\
\cline { 2 - 13 } & CME & ECAM & \multicolumn{1}{|c|}{ ARCOM } & \multicolumn{1}{|c|}{ JCEM } & TOTAL & CME & ECAM & ARCOM & JCEM & TOTAL & $\%$ \\
\hline 2000 & 92 & 36 & 84 & 60 & 272 & 12 & 7 & 19 & 4 & 42 & $15.4 \%$ \\
\hline 2001 & 78 & 37 & 95 & 75 & 285 & 7 & 4 & 20 & 5 & 36 & $12.6 \%$ \\
\hline 2002 & 60 & 38 & 76 & 75 & 249 & 5 & 2 & 8 & 1 & 16 & $6.4 \%$ \\
\hline 2003 & 73 & 18 & 84 & 87 & 262 & 5 & 5 & 13 & 6 & 29 & $11.1 \%$ \\
\hline 2004 & 89 & 36 & 135 & 82 & 342 & 10 & 6 & 23 & 7 & 46 & $13.5 \%$ \\
\hline 2005 & 85 & 35 & 121 & 17 & 258 & 15 & 6 & 17 & 5 & 43 & $16.7 \%$ \\
\hline 2006 & 107 & 36 & 97 & 20 & 260 & 13 & 9 & 25 & 3 & 50 & $19.2 \%$ \\
\hline 2007 & 102 & 37 & 83 & 21 & 243 & 14 & 11 & 14 & 1 & 40 & $16.5 \%$ \\
\hline 2008 & 94 & 36 & 104 & 25 & 259 & 12 & 7 & 18 & 1 & 38 & $14.7 \%$ \\
\hline 2009 & 88 & 36 & 133 & 23 & 280 & 13 & 8 & 28 & 3 & 52 & $18.6 \%$ \\
\hline 2010 & 91 & 34 & 149 & 23 & 297 & 17 & 12 & 23 & 3 & 55 & $18.5 \%$ \\
\hline 2011 & 76 & 36 & 95 & 24 & 231 & 17 & 10 & 16 & 4 & 47 & $20.3 \%$ \\
\hline 2012 & 66 & 36 & 65 & 22 & 189 & 6 & 11 & 6 & 5 & 28 & $14.8 \%$ \\
\hline 2013 & 71 & 54 & 31 & 23 & 179 & 7 & 11 & 3 & 1 & 22 & $12.3 \%$ \\
\hline 2014 & 77 & 34 & 30 & 25 & 166 & 17 & 10 & 5 & 3 & 35 & $21.1 \%$ \\
\hline 2015 & 57 & 37 & 27 & 21 & 142 & 9 & 10 & 3 & 1 & 23 & $16.2 \%$ \\
\hline 2016 & 56 & 41 & 46 & 23 & 166 & 10 & 7 & 7 & 5 & 29 & $17.5 \%$ \\
\hline 2017 & 25 & 35 & 0 & 26 & 86 & 8 & 7 & 0 & 5 & 20 & $23.3 \%$ \\
\hline Total & 1387 & 652 & 1455 & 672 & 4166 & 197 & 143 & 248 & 63 & 651 & $15.6 \%$ \\
\hline
\end{tabular}


Table 8: Total Article on Literature Reviews - Synthesised

\begin{tabular}{|c|c|c|r|r|r|r|r|r|r|r|r|}
\hline \multirow{2}{*}{ YRS } & \multicolumn{3}{|c|}{ TOTAL JOURNALS REVIEWED } & \multicolumn{5}{|c|}{ LITRATURE REVIEWES } \\
\cline { 2 - 14 } & CME & ECAM & ARCOM & \multicolumn{1}{|c|}{ JCEM } & \multicolumn{1}{|c|}{ TOTAL } & CME & ECAM & ARCOM & JCEM & TOTAL & $\%$ \\
\hline 2000 & 92 & 36 & 84 & 60 & 272 & 13 & 1 & 17 & 8 & 39 & $14.3 \%$ \\
\hline 2001 & 78 & 37 & 95 & 75 & 285 & 11 & 6 & 25 & 14 & 56 & $19.6 \%$ \\
\hline 2002 & 60 & 38 & 76 & 75 & 249 & 5 & 7 & 19 & 20 & 51 & $20.5 \%$ \\
\hline 2003 & 73 & 18 & 84 & 87 & 262 & 10 & 3 & 11 & 11 & 35 & $13.4 \%$ \\
\hline 2004 & 89 & 36 & 135 & 82 & 342 & 3 & 2 & 14 & 6 & 25 & $7.3 \%$ \\
\hline 2005 & 85 & 35 & 121 & 17 & 258 & 4 & 0 & 3 & 0 & 7 & $2.7 \%$ \\
\hline 2006 & 107 & 36 & 97 & 20 & 260 & 6 & 1 & 15 & 0 & 22 & $8.5 \%$ \\
\hline 2007 & 102 & 37 & 83 & 21 & 243 & 10 & 1 & 14 & 1 & 26 & $10.7 \%$ \\
\hline 2008 & 94 & 36 & 104 & 25 & 259 & 4 & 4 & 6 & 0 & 14 & $5.4 \%$ \\
\hline 2009 & 88 & 36 & 133 & 23 & 280 & 2 & 1 & 14 & 0 & 17 & $6.1 \%$ \\
\hline 2010 & 91 & 34 & 149 & 23 & 297 & 3 & 3 & 13 & 2 & 21 & $7.1 \%$ \\
\hline 2011 & 76 & 36 & 95 & 24 & 231 & 1 & 3 & 12 & 0 & 16 & $6.9 \%$ \\
\hline 2012 & 66 & 36 & 65 & 22 & 189 & 5 & 1 & 10 & 1 & 17 & $9.0 \%$ \\
\hline 2013 & 71 & 54 & 31 & 23 & 179 & 4 & 4 & 2 & 0 & 10 & $5.6 \%$ \\
\hline 2014 & 77 & 34 & 30 & 25 & 166 & 4 & 1 & 5 & 1 & 11 & $6.6 \%$ \\
\hline 2015 & 57 & 37 & 27 & 21 & 142 & 4 & 1 & 5 & 2 & 12 & $8.5 \%$ \\
\hline 2016 & 56 & 41 & 46 & 23 & 166 & 11 & 1 & 5 & 0 & 17 & $10.2 \%$ \\
\hline 2017 & 25 & 35 & 0 & 26 & 86 & 5 & 2 & 0 & 1 & 8 & $9.3 \%$ \\
\hline Total & 1387 & 652 & 1455 & $\mathbf{6 7 2}$ & $\mathbf{4 1 6 6}$ & 105 & $\mathbf{4 2}$ & $\mathbf{1 9 0}$ & $\mathbf{6 7}$ & $\mathbf{4 0 4}$ & $\mathbf{9 . 7 \%}$ \\
\hline
\end{tabular}


Table 9: General Totals of the Analysis of Articles (Percentage in Parenthesis)

\begin{tabular}{|c|c|c|c|c|c|}
\hline YEAR & $\begin{array}{l}\text { TOTAL } \\
\text { (\%) }\end{array}$ & $\begin{array}{l}\text { QUANTITATIVE } \\
\text { METHOD (\%) }\end{array}$ & $\begin{array}{l}\text { QUALITATIVE } \\
\text { METHOD (\%) }\end{array}$ & $\begin{array}{c}\text { MIXED } \\
\text { METHODS (\%) }\end{array}$ & $\begin{array}{l}\text { LITRATURE } \\
\text { REVIEW (\%) }\end{array}$ \\
\hline 2000 & 100 & $36.4 \%$ & $33.8 \%$ & $15.4 \%$ & $14.3 \%$ \\
\hline 2001 & 100 & $28.4 \%$ & $39.3 \%$ & $12.6 \%$ & $19.6 \%$ \\
\hline 2002 & 100 & $41.0 \%$ & $32.1 \%$ & $6.4 \%$ & $20.5 \%$ \\
\hline 2003 & 100 & $39.3 \%$ & $36.3 \%$ & $11.1 \%$ & $13.4 \%$ \\
\hline 2004 & 100 & $37.4 \%$ & $41.8 \%$ & $13.5 \%$ & $7.3 \%$ \\
\hline 2005 & 100 & $48.1 \%$ & $32.6 \%$ & $16.7 \%$ & $2.7 \%$ \\
\hline 2006 & 100 & $35.0 \%$ & $37.3 \%$ & $19.2 \%$ & $8.5 \%$ \\
\hline 2007 & 100 & $39.9 \%$ & $32.9 \%$ & $16.5 \%$ & $10.7 \%$ \\
\hline 2008 & 100 & $35.5 \%$ & $44.4 \%$ & $14.7 \%$ & $5.4 \%$ \\
\hline 2009 & 100 & $31.4 \%$ & $43.9 \%$ & $18.6 \%$ & $6.1 \%$ \\
\hline 2010 & 100 & $29.6 \%$ & $45.1 \%$ & $18.5 \%$ & $7.1 \%$ \\
\hline 2011 & 100 & $29.4 \%$ & $43.3 \%$ & $20.3 \%$ & $6.9 \%$ \\
\hline 2012 & 100 & $32.3 \%$ & $43.9 \%$ & $14.8 \%$ & $9.0 \%$ \\
\hline 2013 & 100 & $27.4 \%$ & $54.7 \%$ & $12.3 \%$ & $5.6 \%$ \\
\hline 2014 & 100 & $28.3 \%$ & $44.0 \%$ & $21.1 \%$ & $6.6 \%$ \\
\hline 2015 & 100 & $28.2 \%$ & $46.5 \%$ & $16.2 \%$ & $8.5 \%$ \\
\hline 2016 & 100 & $21.7 \%$ & $50.6 \%$ & $17.5 \%$ & $10.2 \%$ \\
\hline 2017 & 100 & $25.6 \%$ & $41.9 \%$ & $23.3 \%$ & $9.3 \%$ \\
\hline MEAN & 100 & $33.1 \%$ & $41.4 \%$ & $16.0 \%$ & $9.5 \%$ \\
\hline
\end{tabular}


Table 10: Demography of the submissions of CME

\begin{tabular}{|l|c|c|c|c|}
\hline Method & UK & USA & Rest of the world & Total \\
\hline Quantitative & $136(10 \%)$ & $54(4 \%)$ & $341(25 \%)$ & $531(39 \%)$ \\
\hline Qualitative & $219(16 \%)$ & $48(3 \%)$ & $286(21 \%)$ & $553(40 \%$ \\
\hline Mixed Methods & $59(4 \%)$ & $16(1 \%)$ & $122(9 \%)$ & $197(14 \%)$ \\
\hline Literature Review & $62(4 \%)$ & $1(0 \%)$ & $43(3 \%)$ & $106(7 \%)$ \\
\hline Subtotal & $\mathbf{4 7 6 ( 3 4 \% )}$ & $\mathbf{1 1 9 ( 9 \% )}$ & $\mathbf{7 9 2 ( 5 7 \% )}$ & $\mathbf{1 3 8 7 ( 1 0 0 \% )}$ \\
\hline
\end{tabular}

Table 11: Demography of the submissions of ECAM

\begin{tabular}{|l|c|c|c|c|}
\hline Method & UK & USA & Rest of the world & Total \\
\hline Quantitative & $59(9 \%)$ & $13(2 \%)$ & $135(21 \%)$ & $207(32 \%)$ \\
\hline Qualitative & $122(19 \%)$ & $22(3 \%)$ & $116(18 \%)$ & $260(40 \%)$ \\
\hline Mixed Methods & $55(8 \%)$ & $3(0 \%)$ & $85(13 \%)$ & $143(21 \%)$ \\
\hline Literature Review & $18(3 \%)$ & $4(1 \%)$ & $20(3 \%)$ & $42(7 \%)$ \\
\hline Subtotal & $\mathbf{2 5 4 ( 3 9 \% )}$ & $\mathbf{4 2 ( 6 \% )}$ & $\mathbf{3 5 6 ( 5 5 \% )}$ & $\mathbf{6 5 2 ( 1 0 0 \% )}$ \\
\hline
\end{tabular}

Table 12: Demography of the submissions of JCEM

\begin{tabular}{|l|c|c|c|c|}
\hline Method & UK & USA & Rest of the world & Total \\
\hline Quantitative & $4(1 \%)$ & $176(26 \%)$ & $95(14 \%)$ & $275(41 \%)$ \\
\hline Qualitative & $5(1 \%)$ & $176(26 \%)$ & $87(13 \%)$ & $268(40 \%)$ \\
\hline Mixed Methods & $4(1 \%)$ & $43(6 \%)$ & $16(2 \%)$ & $63(10 \%)$ \\
\hline Literature Review & $1(0 \%)$ & $55(8 \%)$ & $10(1 \%)$ & $66(9 \%)$ \\
\hline Subtotal & $\mathbf{1 4 ( 2 \% )}$ & $\mathbf{4 5 0 ( 6 7 \% )}$ & $\mathbf{2 0 8 ( 3 1 \% )}$ & $\mathbf{6 7 2 ( 1 0 0 \% )}$ \\
\hline
\end{tabular}

Table 13: Demography of the submissions of ARCOM

\begin{tabular}{|l|c|c|c|c|}
\hline Method & UK & USA & Rest of the world & Total \\
\hline Quantitative & $236(16 \%)$ & $8(1 \%)$ & $159(11 \%)$ & $403(28 \%)$ \\
\hline Qualitative & $404(28 \%)$ & $3(0 \%)$ & $207(14 \%)$ & $614(42 \%)$ \\
\hline Mixed Methods & $157(11 \%)$ & $2(0 \%)$ & $89(6 \%)$ & $248(17 \%)$ \\
\hline Literature Review & $142(10 \%)$ & $2(0 \%)$ & $46(3 \%)$ & $190(13 \%)$ \\
\hline Subtotal & $\mathbf{9 3 9 ( 6 5 \% )}$ & $\mathbf{1 5 ( 1 \% )}$ & $\mathbf{5 0 1 ( 3 4 \% )}$ & $\mathbf{1 4 5 5 ( 1 0 0 \% )}$ \\
\hline
\end{tabular}

